\title{
Noninvasive monitoring of respiratory mechanics during sleep
}

\author{
R. Farré*, J.M. Montserrat", D. Navajas*
}

\begin{abstract}
Noninvasive monitoring of respiratory mechanics during sleep. R. Farré, J.M. Montserrat, D. Navajas. C ERS Journals Ltd 2004.

ABSTRACT: The sleep apnoea-hypopnoea syndrome is characterised by recurrent obstructions of the upper airway, resulting in sleep disruption and arterial oxygen desaturations. Noninvasive assessment of respiratory mechanics during sleep is helpful in facilitating the diagnosis and treatment of patients with sleep apnoea-hypopnoea syndrome. This series summarises the different tools that are currently available to noninvasively assess respiratory mechanics during sleep breathing disturbances. These techniques are classified according to the main variable monitored: ventilation, breathing effort or airway obstruction. Changes in patient ventilation are assessed by recording flow or volume signals by means of pneumotachographs, thermistors or thermocouples, nasal prongs or thoraco-abdominal bands. Common tools to noninvasively assess breathing efforts are the thoraco-abdominal bands and the pulse transit time technique. Upper airway obstruction is noninvasively characterised by its upstream resistance and its critical pressure or by means of the forced oscillation technique. Given the technical and practical limitations of each technique, combining different tools improves the reliability and robustness of patient assessment during sleep.
\end{abstract}

Eur Respir J 2004; 24: 1052-1060.
*Unitat Biofisica i Bioenginyeria, Facultat Medicina, Universitat Barcelona-Institut d'Investigacions Biomediques August Pi Sunyer (IDIBAPS), and ${ }^{\#}$ Sleep Laboratory, Hospital Clinic Provincial-IDIBAPS, Barcelona, Spain.

Correspondence: R. Farré, Unitat de Biofisica i Bioenginyeria, Facultat de Medicina, Casanova 143, E-08036 Barcelona, Spain.

Fax: 34934024516

E-mail: rfarre@ub.edu

Keywords: Monitoring, sleep apnoea diagnosis and treatment, sleep-disordered breathing, upper airway obstruction, upper airway patency

Received: June 162004

Accepted after revision: August 22004

This work was supported in part by Ministerio de Ciencia y Tecnología (SAF2002-03616 and SAF2003-01334) and Ministerio de Sanidad y Consumo(RedRespira-ISCiii-RTIC-03/11), Spain.
The study of the sleep apnoea-hypopnoea syndrome (SAHS) has made considerable advances in the last decade. Although details of the basic mechanisms causing sleep disorders are still unclear, the research carried out in recent years has allowed the characterisation of the different sleep events experienced by SAHS patients. This has been possible, in part, due to the development and refinement of noninvasive sensors and techniques for assessing the sleep architecture, ventilation, blood oxygen saturation, airway patency and inspiratory effort.

Sleep in patients with SAHS is characterised by a disruption of sleep, which is partly the cause of diurnal somnolence, and by repetitive events of hypoxaemia, which could lead to long-term cardiovascular consequences. Both the disruption of sleep architecture and the recurrent episodes of hypoxaemia are caused by airway obstructions due to increased upper airway collapsibility in the absence of wakefulness $[1,2]$. Given the fact that airway obstruction plays a central role in the sleep disturbances of SAHS patients, methods for noninvasively assessing respiratory mechanics during sleep are useful in routine polysomnography. In this series, the current authors focus on the noninvasive assessment of the three types of variables most involved in the mechanics of breathing: ventilation, inspiratory effort and upper airway obstruction.

\section{Noninvasive assessment of ventilation}

Abnormal ventilation during sleep is an obvious manifestation of SAHS. Indeed, ventilation is usually reduced as a result of a partial or total obstruction of the upper airway caused by an increased collapsibility. The obstructive ventilatory events found in SAHS patients are classified into three main categories: apnoeas, hypopnoeas and flow limitation [3, 4]. First, an apnoea is a cessation of flow resulting from a complete obstruction of the upper airway. Secondly, hypopnoeas, which usually occur in the case of a partial occlusion of the upper airway, are breathing cycles with reduced ventilation. Therefore, assessing hypopnoeas requires a measuring system allowing the quantification of ventilation, for instance, by means of the volume changes computed by integration of the breathing flow signal. However, it should be noted that assessing the changes in amplitude of the breathing flow signal is only an indirect estimation of ventilation, since the potential effects of changes in frequency and inspiratory/ expiratory ratio are not considered. Thirdly, flow-limitation events are characterised by a flattened profile of the inspiratory flow waveform resulting from the collapsibility of the upper airway wall. Accordingly, airflow is a physiological variable that can easily detect apnoeas, hypopnoeas and flow limitation. 
The gold-standard device to measure flow is the pneumotachograph. However, the use of a pneumotachograph during sleep requires the patient to wear a nasal or face mask. Although pneumotachographs are regularly used in the sleep research setting, they are not suitable for routine diagnostic sleep studies where the patients do not wear a mask. Therefore, non-obtrusive sensors to detect breathing flow are especially suitable for this application. Two types of small and simple devices, placed close to the airway opening, are used to provide surrogate flow signals: thermistors/thermocouples and nasal prongs. The ventilation disturbances caused by obstructive sleep events are also monitored by indirect estimation of lung volume by means of thoraco-abdominal bands.

\section{Thermistors and thermocouples}

Thermistors and thermocouples are small-sized sensors whose electrical characteristics (resistance and voltage, respectively) depend on their temperature. To assess breathing flow, the device is placed close to the airway opening, i.e. the nose or mouth. Flow detection is monitored by measuring the variation in the electrical property of the sensor, as this is exposed to the temperature changes in the flow at the airway opening (room-air temperature during inspiration and $\approx 37^{\circ} \mathrm{C}$ during expiration).

Given the complex physics governing the airflow measurement with thermistors and thermocouples, these devices provide a semiquantitative signal [5]. The main limitations of these thermal devices are that their dynamic response is poor (slow response), and that the relationship between their electrical signal and airflow is nonlinear and largely depends on the exact position at the airway opening. Accordingly, thermistors and thermocouples are not suitable to accurately quantify the magnitude of flow [5]. By contrast, these thermal sensors are an excellent device to detect apnoeas. As illustrated in figure 1, which shows data from a bench study, the thermistor signal is not able to accurately reproduce the magnitude and waveform of the breathing airflow. Indeed, the figure shows that the thermistor signal was almost the same, regardless of changing the amplitude and waveform of the recorded flow. Despite these limitations, semiquantitative thermal devices are widely employed in clinical routine owing to their simple use, small size and patient tolerance.

\section{Nasal prongs}

Assessment of breathing flow during sleep is also carried out by recording pressure at the nostrils [6]. To this end, conventional nasal prongs, which are designed to provide long-term oxygen therapy, are connected to a pressure transducer. The rationale of the method is that the airflow turbulences at the nostrils induce a pressure that is directly related to the magnitude of flow. The setting is extremely simple and has an excellent dynamic response. However, one limitation of this device is that the relationship between nasalprongs pressure and airflow is not linear [7], as shown in figure 2. Given the quadratic pressure-flow relationship in the nasal prongs, this device may result in an overestimation of the flow magnitude (comparison between fig. $2 \mathrm{a}$ and $\mathrm{b}$ ). Nevertheless, the nasal-prongs signal can be linearised $[8,9]$ to obtain an excellent surrogate signal of flow (comparison between fig. 2a and c).

Given their fast response, nasal prongs are suitable to detect flow limitation because the device is able to track the details of the inspiratory waveform contour, particularly if the signal is linearised. However, the calibration factor shows a considerable intra-subject variability because it depends on the exact position of the prongs at the nostrils. Consequently, the device cannot be used to quantitatively estimate flow throughout the night. The breathing-pattern changes detected in a given sleep event should be compared with the signal in the previous normal cycles. Nasal prongs have two potential drawbacks in practice. First, the device cannot obviously detect mouth breathing, with the result that the flow signal is completely lost when the patient breathes through the mouth, or partially lost when the patient inspires through the nose
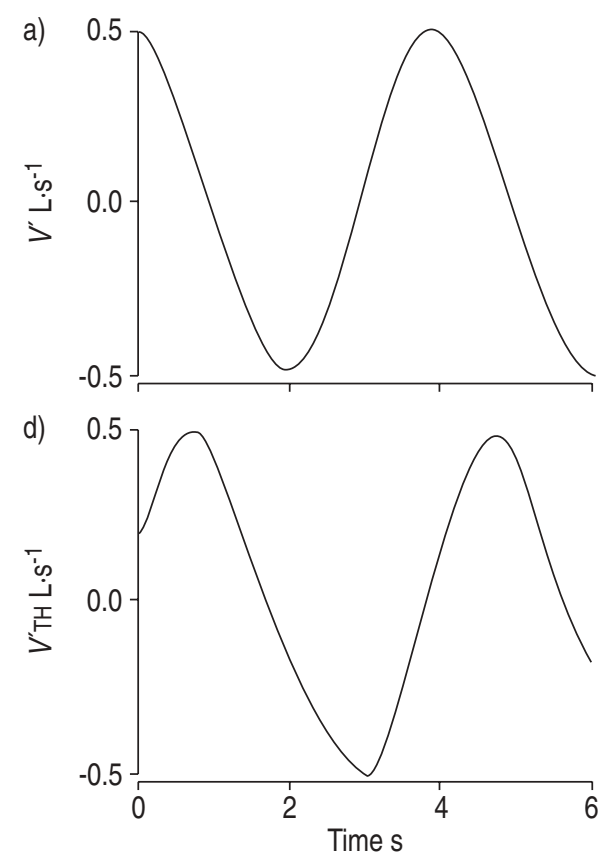

b)

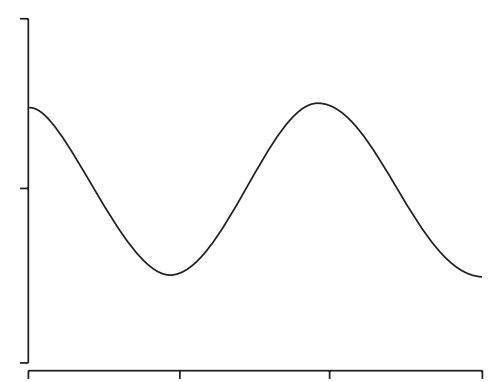

e)

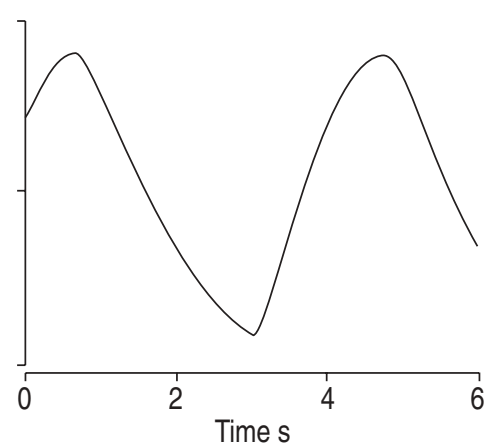

c)

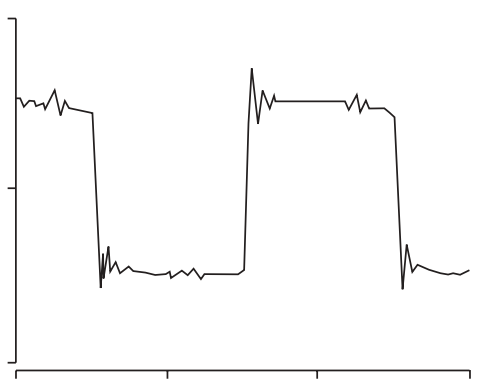

f)

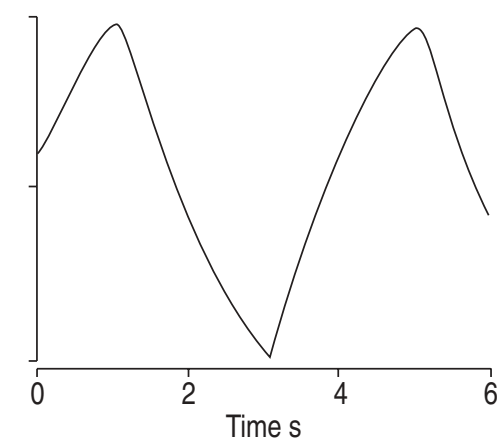

Fig. 1. - a, b, c) Actual flows measured by a reference pneumotachograph $\left(V^{\prime}\right)$. d, e, f) Signal provided by a conventional thermistor $\left(V^{\prime} \mathrm{TH}\right)$ when assessing the corresponding actual flow (a, b, c, respectively) in a bench model. Modified from [5] with permission. 


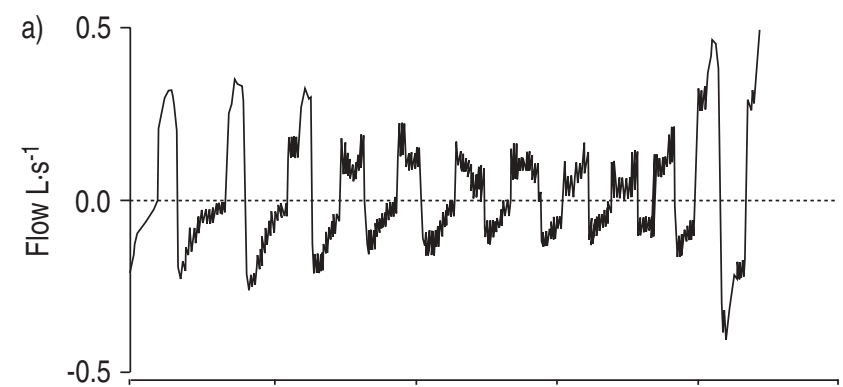

b)

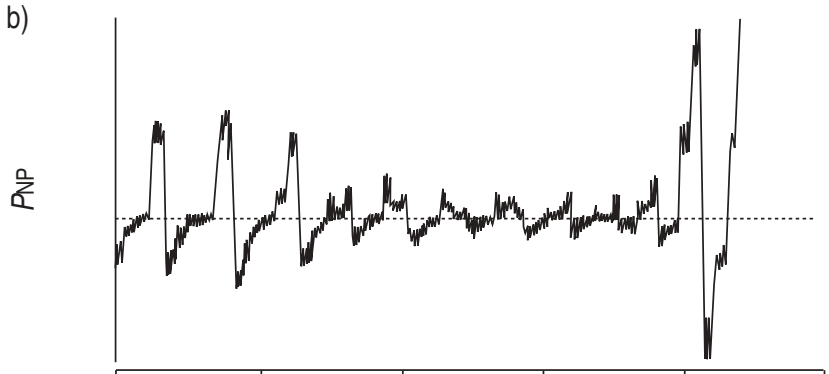

c)

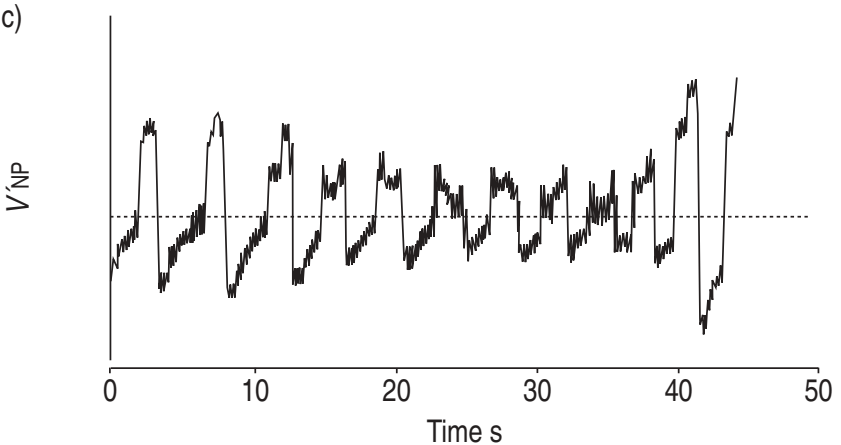

Fig. 2. -a) Flow measured with a pneumotachograph during a hypopnoea in a bench test. b) Simultaneous nasal pressure signal $(P \mathrm{NP})$ recorded with nasal prongs. c) Linearised flow signal ( $\left.V^{\prime} \mathrm{NP}\right)$ obtained by computing the square root of the pressure recorded by the nasal prongs. Modified from [8] with permission.

and expires through the mouth [10]. Secondly, it has been suggested that, in some patients, nasal prongs with inadequate size could induce an increase in airway resistance [11]. Despite their potential artefacts, this simple device has proved to be particularly useful in monitoring respiratory sleep disturbances in SAHS [12-14]. In fact, since its initial use in research studies, it has been progressively employed as an alternative or complement to thermistors and thermocouples in clinical routine. An illustrative polysomnographic recording to compare the performance of thermistors and nasal prongs is depicted in figure 3: the nasal prongs provided a more detailed assessment of the changes in breathing flow during the sleep event.

\section{Inductive plethysmography}

Lung ventilation can be noninvasively monitored by assessing the change in the cross-sectional areas of the thoracic and abdominal compartments, assuming a twocompartment model of the thoracic cage [15]. The method, which does not interfere with patient sleep, is based on the use of two bands, one placed around the thorax and another placed around the abdomen. Each band includes an inductive coil whose electromagnetic properties depend on the area enclosed by the band and, therefore, on the section of the
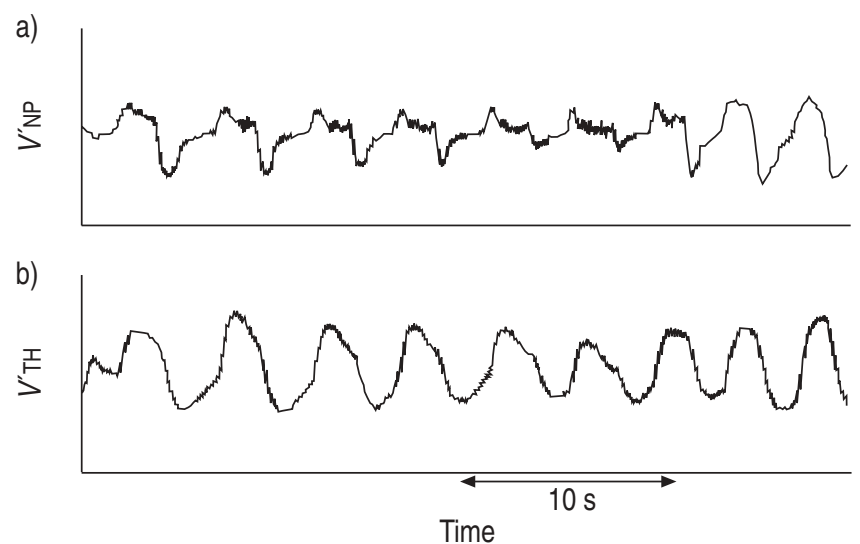

Fig. 3.-Flow signal estimated simultaneously by measurements of nasal pressure assessed by a) nasal prongs ( $\left.V^{\prime} N P\right)$ and by b) a thermistor signal $\left(V^{\prime} \mathrm{TH}\right)$ in a sleep apnoea-hypopnoea syndrome patient.

thoracic or the abdominal compartments, respectively. This method, which is known as respiratory inductive plethysmography, allows the accurate estimation of ventilation,
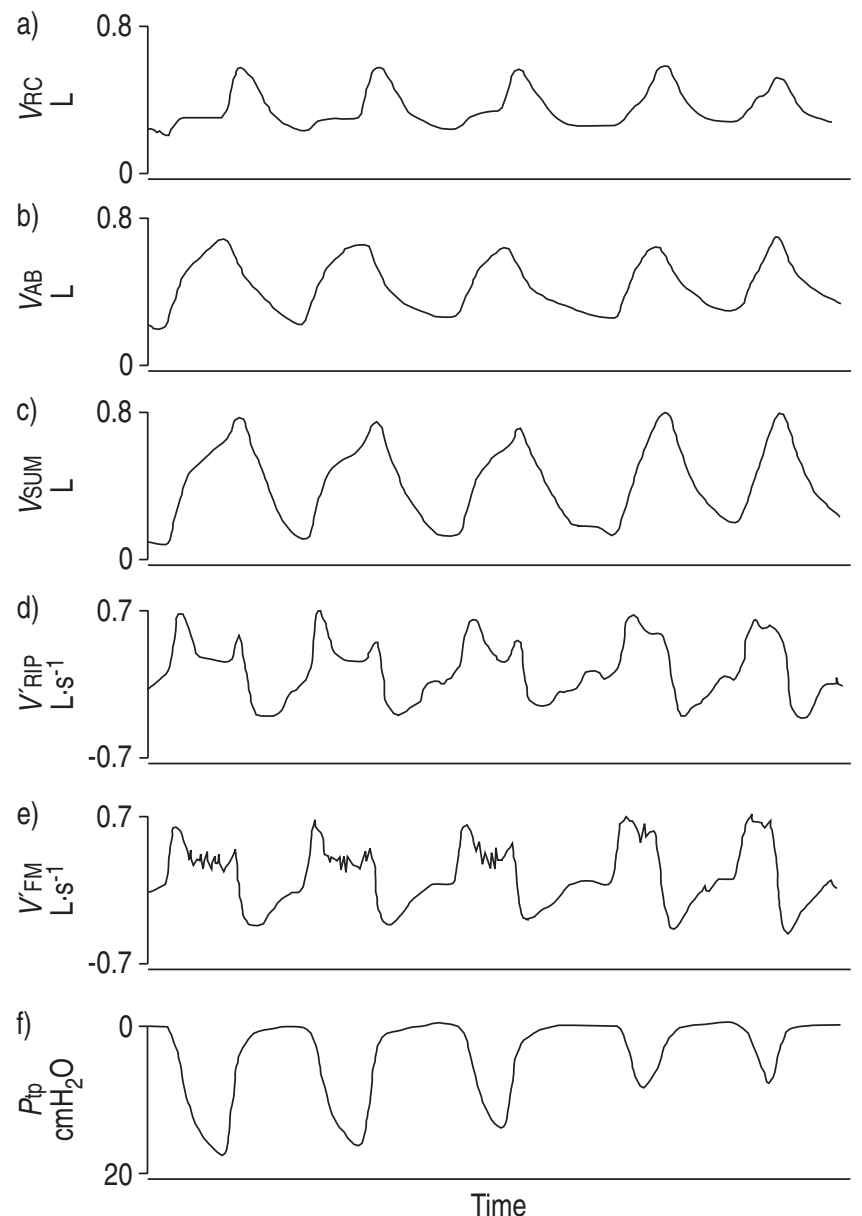

Fig. 4.-Example of the signals recorded by inductive plethysmography during a flow-limitation event in a patient with sleep apnoeahypopnoea syndrome. a) $V_{\mathrm{RC}}$, b) $V_{\mathrm{AB}}$ and c) $V_{\mathrm{SUM}}$ are the rib cage, the abdominal and the total volume signals provided by the inductive bands, respectively. d) $V^{\prime}$ RIP is the flow signal derived from $V_{\text {SUM. e) }}$ $V^{\prime}$ FM is actual nasal flow measured by a pneumotachograph. f) $P$ tp is transpulmonary pressure. Modified from [20] with permission. 
provided that calibrations of the thoracic and the abdominal bands are carried out by means of a reference-volume device (pneumotachograph or spirometer) [16]. Inductive plethysmography has been successfully used in studies under controlled conditions [17-20]. Figure 4 shows an example of the flow recording derived from inductive plethysmography compared with actual nasal flow during a flow-limitation event in a patient with SAHS. A practical problem of inductive plethysmography is that the calibration gains depend on the position of the bands around the thorax and abdomen. Consequently, unattended application of inductive plethysmography throughout the night runs the risk of providing inaccurate volume values, caused by displacement of the bands due to patient movement during sleep. Inductive plethysmography accurately assesses the magnitude of hypopnoeas, provided that the signal observed during a given obstructive event is compared with that of the previous normal cycles.

\section{Noninvasive assessment of inspiratory effort}

As a consequence of an obstruction of the upper airway, a patient with obstructive SAHS exerts increased inspiratory efforts in an attempt to maintain ventilation. Accordingly, monitoring inspiratory muscle activity is useful to estimate airway obstruction. However, the gold-standard signal to quantitatively assess the inspiratory pressure developed by the inspiratory muscles, i.e. pleural pressure, demands the use of

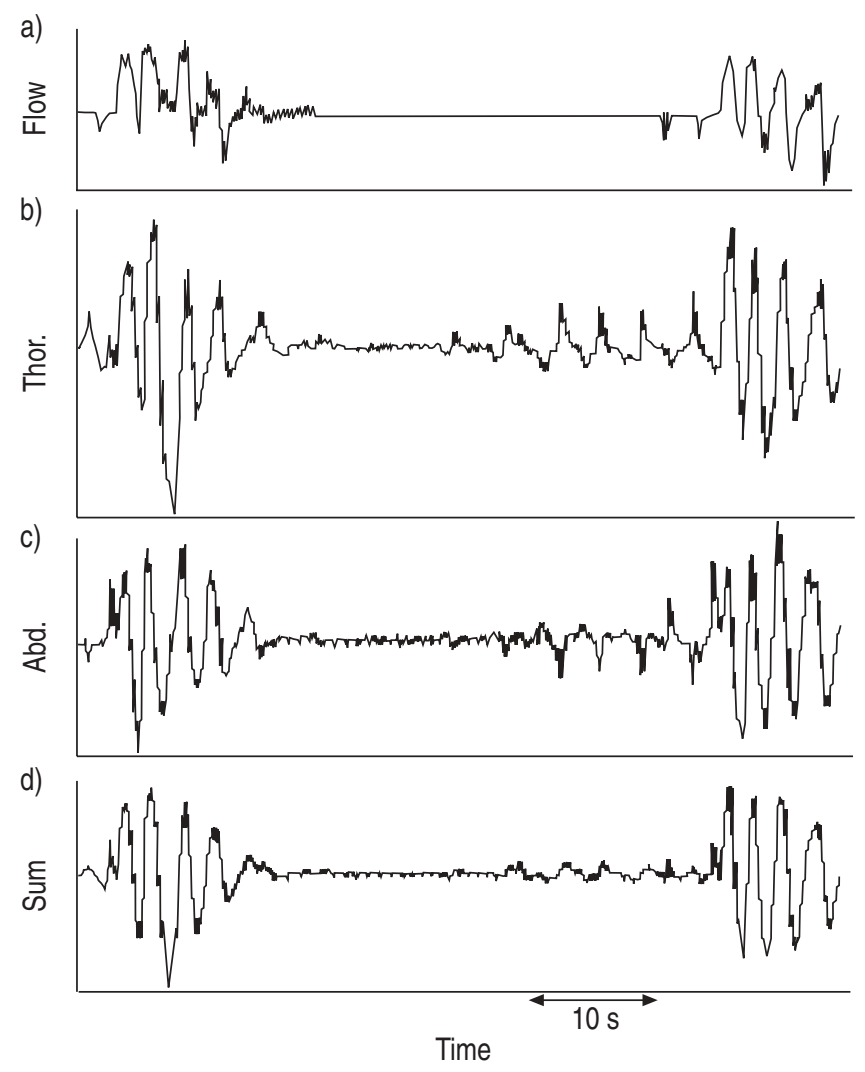

Fig. 5. - Signals recorded during an apnoea in a patient with sleep apnoea-hypopnoea syndrome. The first part of the apnoea was central and the last part was obstructive. a) Flow was estimated with nasal prongs recording nasal pressure. b) Thor. and c) Abd. are the signals provided by the thoracic and the abdominal bands of a respiratory inductive plethysmograph, respectively. d) Sum is the addition of the signals provided by the thoracic and the abdominal bands. an invasive oesophageal balloon or catheter. As this technique is not applicable in routine, indirect methods to noninvasively estimate inspiratory effort have been developed for clinical application.

\section{Thoraco-abdominal bands}

Besides their application to estimate changes in ventilation, thoraco-abdominal bands are mainly used to semiquantitatively assess the magnitude of the inspiratory efforts in SAHS [21-24]. The rationale is based on the analysis of the amplitude of the swing movements of the thoracic and the abdominal compartments, and on the comparison of the synchrony between both movements. In the case of a central apnoea, neither the thoracic nor the abdominal compartment move, with the result that the signals from both bands and their sum are nil. By contrast, during an obstructive apnoea, there is a reduction and an asynchrony of the thoracic and abdominal movements, resulting in a decrease in the amplitude of the sum of the signals from both bands. Consequently, central and obstructive apnoeas can be distinguished by inspection of the signals of each band and of their addition. This is illustrated in figure 5, which shows a mixed apnoea in a SAHS patient. The first part of this apnoea was central (absence of thoracic and abdominal movements) and its last part was obstructive (out-of-phase thoracic and abdominal movements). In both parts of the apnoea, the sum of the thoracic and abdominal movements was virtually nil.

Given that this application of thoraco-abdominal bands is

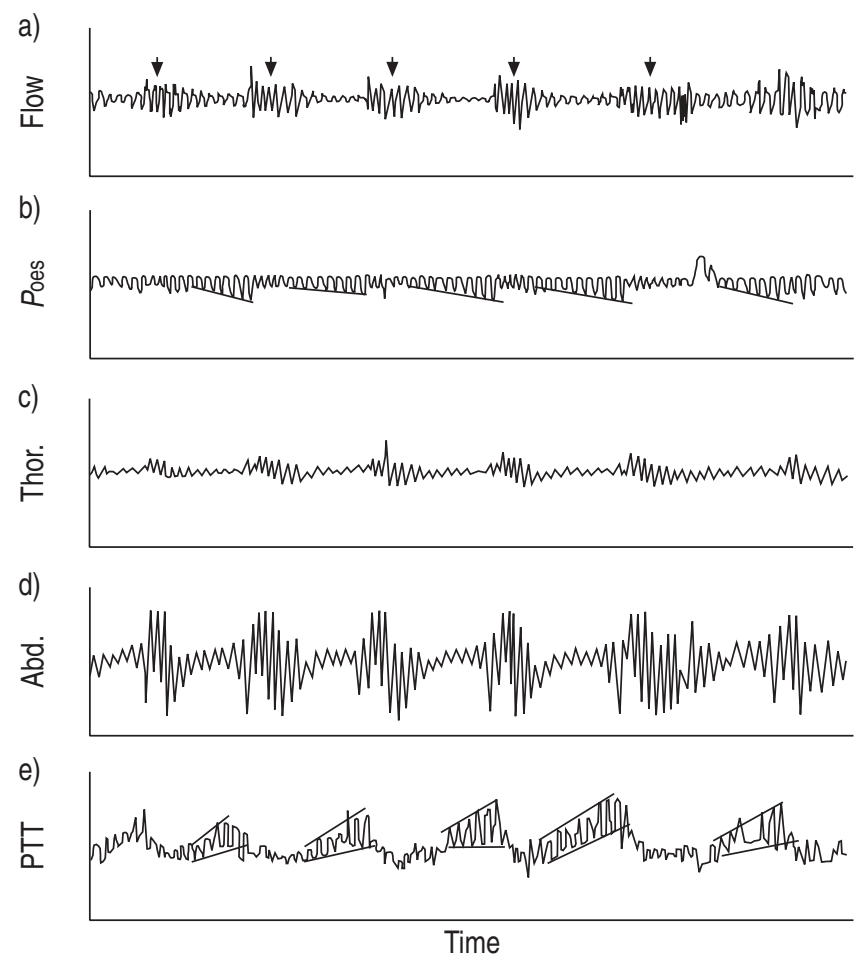

Fig. 6.-Sequence of obstructive and normal breathing events in a patient with sleep apnoea-hypopnoea syndrome. c) Thor. and d) Abd. are the signals from the thoracic and abdominal bands of a respiratory inductive plethysmograph, respectively. The amplitudes of pulse transit time (PTT; e) swings tend to parallel those of the oesophageal pressure $\left(P_{\mathrm{oes}} ; \mathrm{b}\right)$ both during obstructive respiratory events (indicated by lines) and normal breathing (marked with arrows; a), with the exception of the first and fifth events. Modified from [39] with permission. 
semiquantitative, technologies simpler than inductive plethysmography are more commonly employed to detect force and deformation in the bands, as follows: strain gauges, piezoelectric transducers or pneumatic bands [25-28]. Finally, other semiquantitative methods are used, although less frequently, to detect respiratory movements during sleep, as follows: thoracic impedance, electromyography of the respiratory muscles or the air-mattress system [29-33].

\section{Pulse transit time technique}

The pulse transit time (PTT) technique is an innovative method to assess sleep disturbances. In addition to its ability to detect autonomic arousals [34], PTT is a tool that can be used to noninvasively monitor respiratory effort [35-38]. The technique is based on measuring the time required for the arterial pulse wave to travel between two points in the arterial tree, specifically, from the moment when the pulse leaves the aortic valve, identified by the $\mathrm{R}$ wave on the ECG, to the time when it reaches the vessels in the finger, identified by the pulse wave detected by the pulse-oximeter sensor. Accordingly, the method only requires the use of conventional ECG leads, a pulse oximeter and a computation unit. The rationale for detecting inspiratory effort from PTT is that the pulse wave speed depends on the vessel stiffness, which is, in turn, determined by blood pressure. During airway obstructions, the increased swings in intrathoracic pressure modulate blood pressure and, consequently, induce parallel changes in PTT, as shown in figure 6. Although individual PTT values do not correlate with the absolute values of pleural pressure, their oscillations estimate the swings of pleural pressure that occur during the obstructive breaths with high sensitivity and specificity [39]. To date, this technique is not widely applied in routine.

\section{Noninvasive assessment of airway obstruction}

Although flow and inspiratory-effort disturbances are the clearest manifestations of SAHS, and, accordingly, are the most widely monitored in polysomnography, both disturbances are due to an increase in upper airway obstruction. In addition to assessing secondary signals, such as flow and effort, direct measurement of airway obstruction with a noninvasive procedure is helpful in characterising SAHS.

The application of the conventional concept of airway resistance in SAHS is not straightforward. Indeed, flow resistance in a conduit with rigid walls is the quotient between the pressure drop along the conduit and the associated airflow. However, the upper airway in patients with SAHS is highly collapsible and its patency depends on the transmural pressure across the airway wall. Accordingly, the flow through the airway depends not only on the pressure drop across it (nasal pressure minus tracheal pressure), but also on the absolute values of both nasal pressure (greater than zero if continuous positive airway pressure (CPAP) is applied) and tracheal pressure (which depends on the inspiratory effort). This makes it particularly difficult to characterise the degree of obstruction of the collapsible upper airway. This difficulty is increased in routine clinical practice where noninvasive measurements are mandatory.

Given that recording pharyngeal or oesophageal pressure ( $P$ oes) is excluded in clinical routine, airway obstruction should be estimated from measurements of nasal pressure and airflow. This is achieved by two different approaches. One procedure is the characterisation of the upper airway mechanics by its upstream resistance and its critical pressure, according to the Starling resistor model [40]. The other procedure is to assess airway resistance by means of the forced oscillation technique (FOT) [41]. As both techniques require the accurate measurement of flow, i.e. the use of a pneumotachograph, a nasal mask is required. This renders the
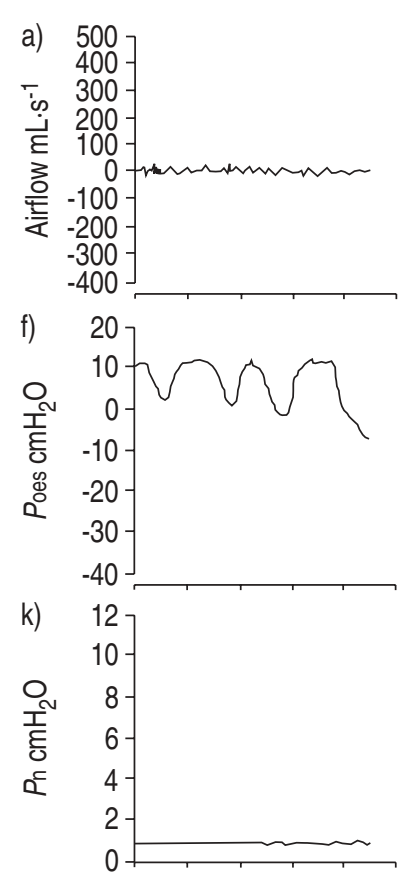

b)

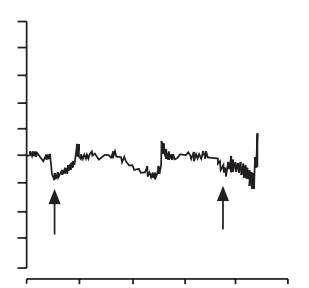

g)

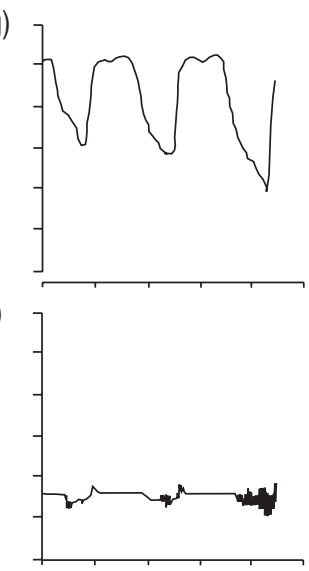

c)

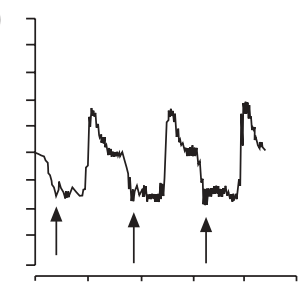

h)

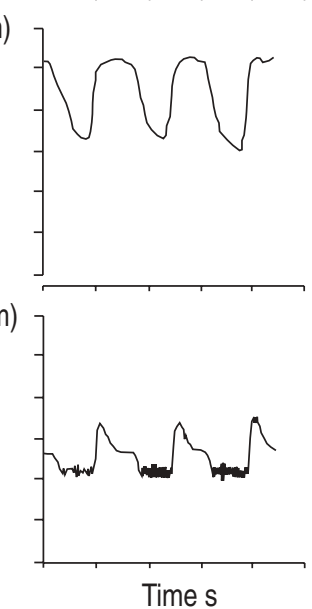

d)

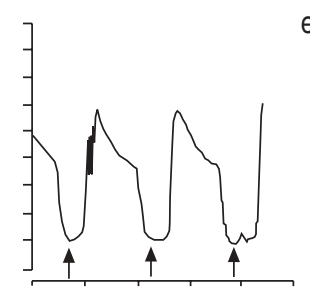

i)

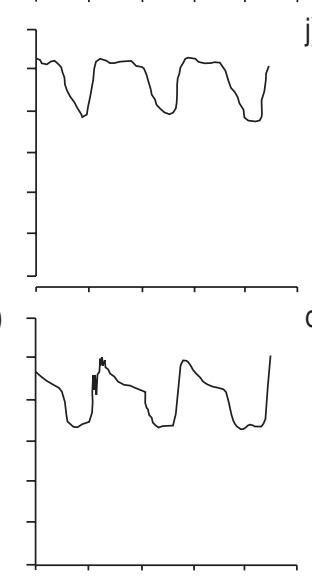

e)

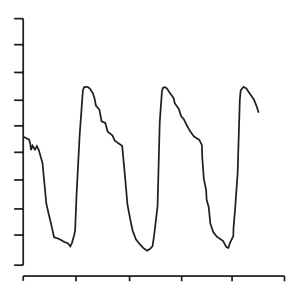

j)

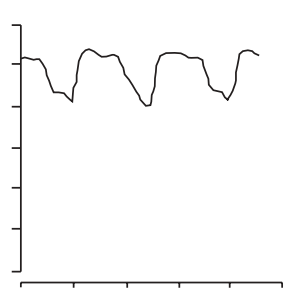

0)

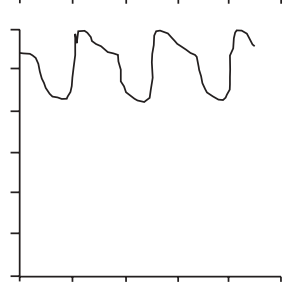

Fig. 7. - Airflow (negative during inspiration), oesophageal pressure $\left(P_{\mathrm{oes}}\right)$ and nasal pressure $\left(P_{\mathrm{n}}\right)$ when applying different continuous positive airway pressure (CPAP) values to a patient with sleep apnoea-hypopnoea syndrome (CPAP value 1: a, f, k; CPAP value 2: b, g, 1; CPAP value 3: $\mathrm{c}, \mathrm{h}, \mathrm{m}$; CPAP value 4: d, i, n; CPAP value $5: \mathrm{e}, \mathrm{j}, \mathrm{o}$ ). The arrows in the airflow curves $(\mathrm{b}, \mathrm{c}$, and $\mathrm{d}$ ) indicate the maximal inspiratory flow at each level of CPAP. Modified from [40] with permission. 
estimation of airway obstruction a little more cumbersome for the patient than the use of a thermistor or thermocouple, or thoraco-abdominal bands. However, these two techniques for directly characterising airway obstruction do not require increased patient instrumentation during the routine setting of CPAP titration.

Upstream resistance and critical pressure of the upper airway

This technique is performed during the application of different levels of positive pressure to the airway. It consists of measuring the maximal inspiratory flow corresponding to each nasal pressure applied, as illustrated in figure 7. At a low nasal pressure, the upper airway is collapsed and there is no flow. As CPAP is increased beyond the upper airway critical pressure $(P$ crit), which is defined as the minimum intraluminal pressure to keep the airway open, inspiration is possible but with flow limitation [40]. According to the Starling resistor model, there is a linear relationship between nasal pressure $(P$ n $)$, peak inspiratory flow $\left(V^{\prime} \max \right)$ and $P$ crit:

$$
V^{\prime} \max =(P \mathrm{n}-P \text { crit }) / \text { Rup }
$$

where Rup is the upstream resistance of the collapsible upper airway during flow limitation. Consequently, from the $P$ n and $V^{\prime} \max$ data recorded during application of different CPAP values, it is possible to characterise the mechanical properties of the upper airway by computing Pcrit and Rup (fig. 8).

The procedure for assessing $P$ crit and $R$ up, which was initially applied during the full CPAP titration process, has recently been optimised to allow the assessment of upper airway mechanics with a simplified protocol [42]. The characterisation of the upper airway properties by means of $P$ crit and Rup allows the quantification of the role played by static and dynamic obstructions, respectively. Static obstruction is determined by the properties of the airway wall and the surrounding tissues, whereas Rup depends both on the airway wall properties and on gas dynamics [43]. The application of this technique has shown that upper airway collapsibility is reduced by patient weight loss, after uvulopalatopharyngoplastia or sedation [44-46]. Moreover, $P$ crit has been measured to differentiate between the active and passive mechanisms determining apnoeas [47].

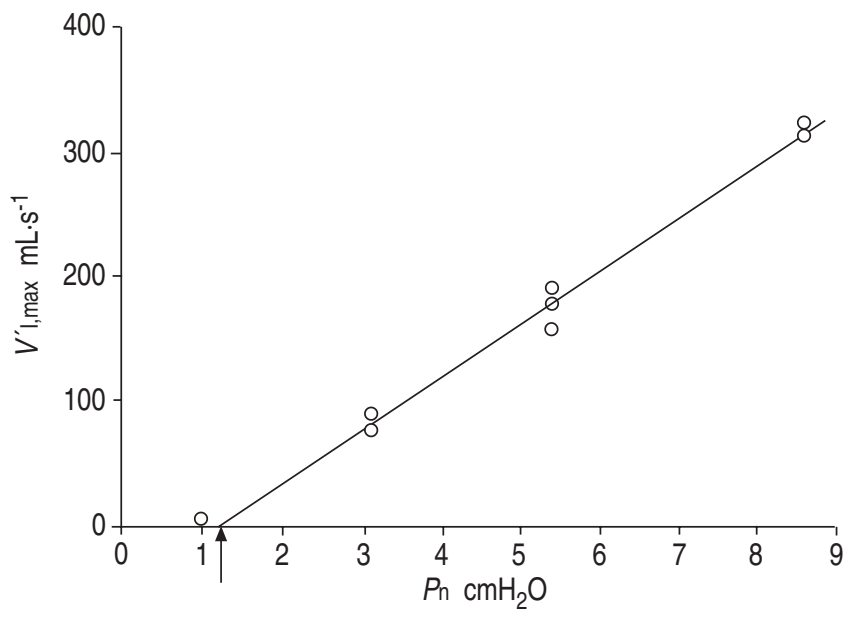

Fig. 8. - Relationship between the maximal inspiratory flow ( $\left.V^{\prime} I, \max \right)$ and nasal pressure $\left(P_{n}\right)$ from the recordings in figure 7 . The arrow represents the critical pressure of the upper airway $\left(+1.2 \mathrm{cmH}_{2} \mathrm{O}\right)$. The reciprocal of the slope $(\mathrm{r}=0.99)$ is the upstream resistance of the upper airway. Modified from [40] with permission.

\section{Forced oscillation technique}

The FOT is based on applying a low-amplitude highfrequency oscillation at the airway opening (i.e. the nasal mask) and on recording pressure and flow. The oscillation is applied during spontaneous breathing by means of an external generator connected to the mask. The relationship between the amplitude of the oscillatory pressure and the corresponding oscillatory flow is an index of airway impedance. The rationale for avoiding the measurement of transpulmonary pressure is that the inspiratory muscles do not contribute towards generating oscillatory flow at the high FOT frequency (5-20 Hz in sleep studies). In the case of an open airway, FOT measures total respiratory impedance,
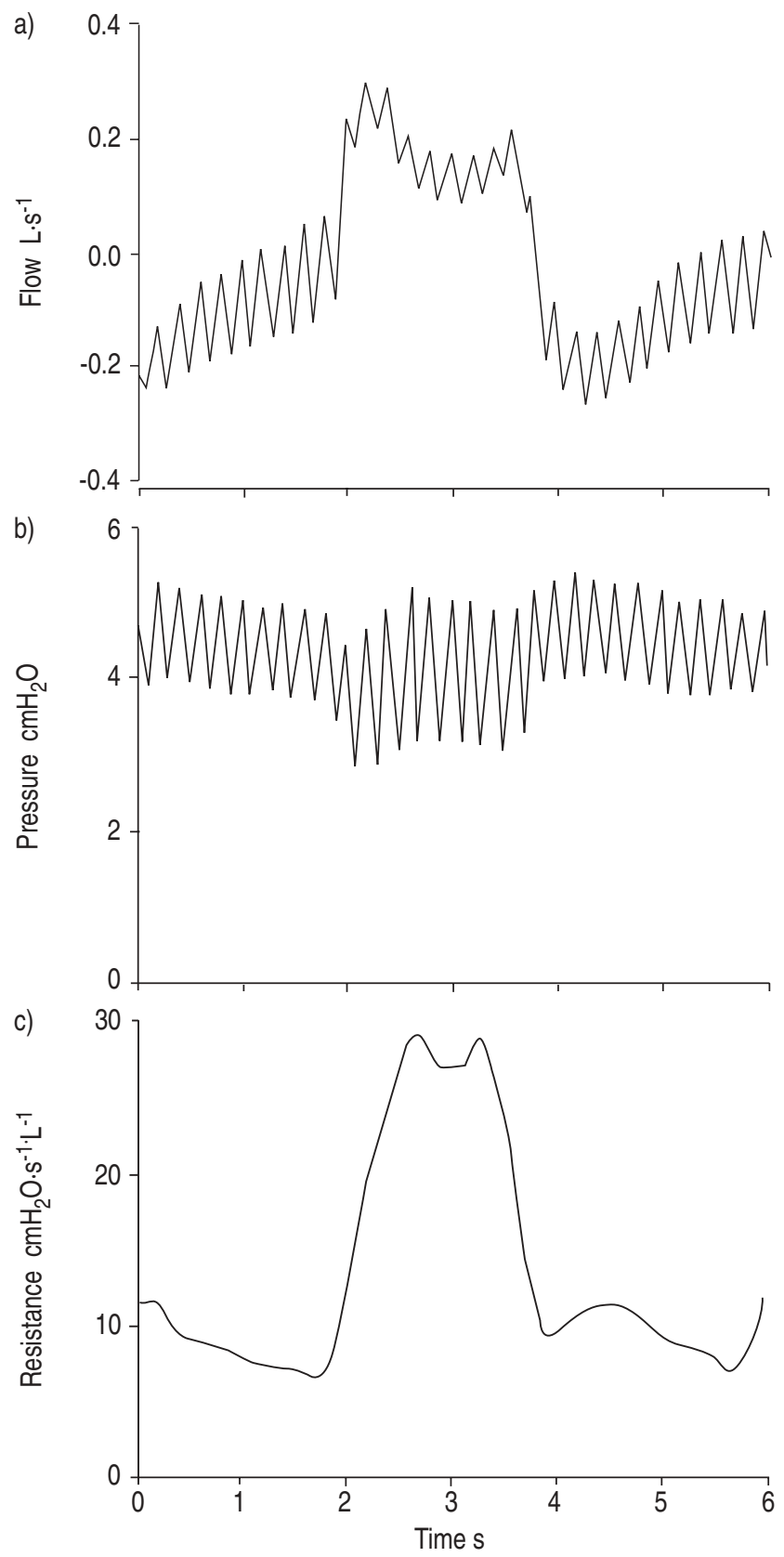

Fig. 9. - a) Flow, b) nasal pressure and c) resistance measured by forced oscillation $(5 \mathrm{~Hz})$ in a sleep apnoea-hypopnoea syndrome patient during application of continuous positive airway pressure. 


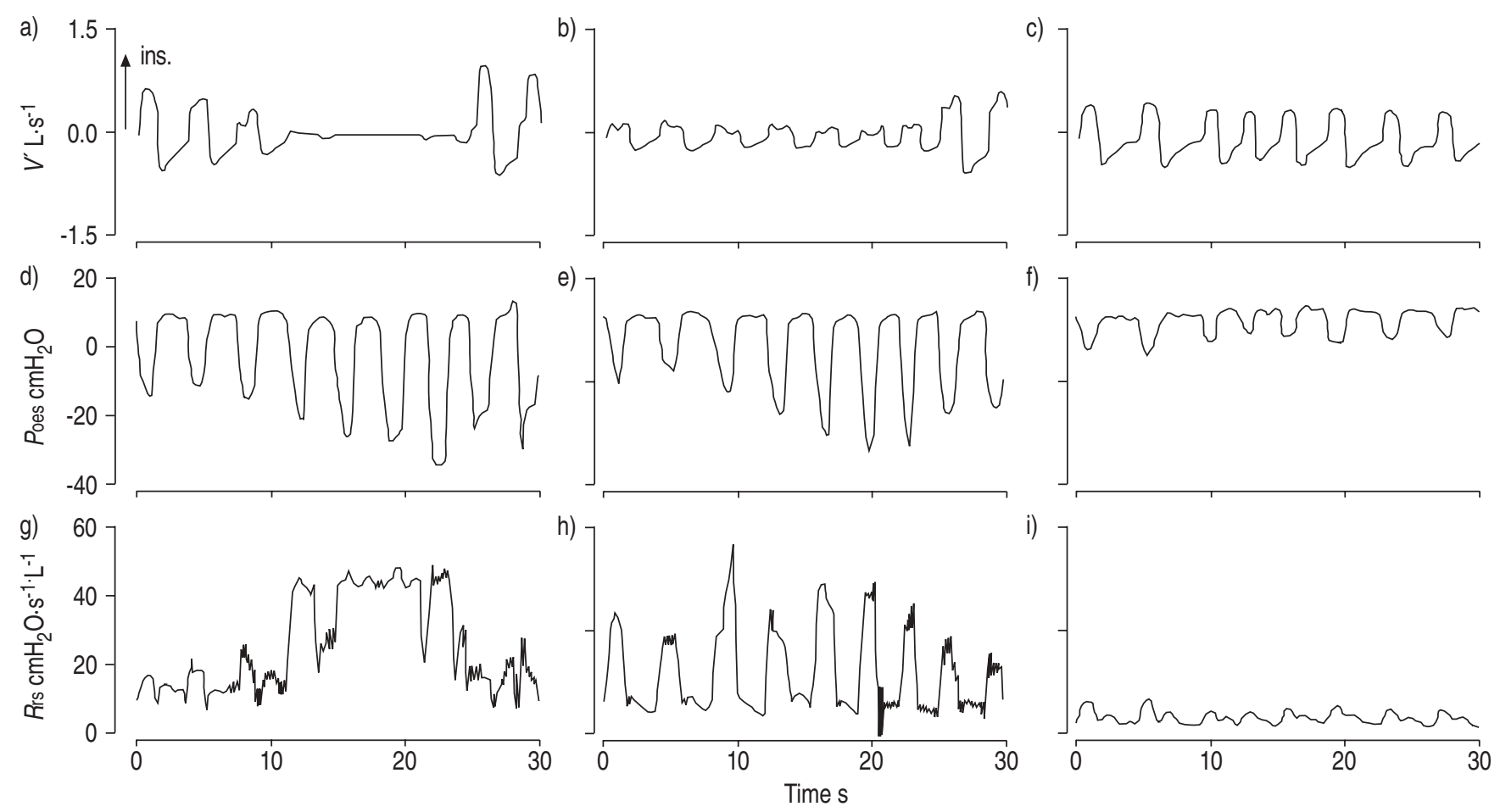

Fig. 10. - Nasal flow $\left(V^{\prime}\right)$, oesophageal pressure $\left(P_{\text {oes }}\right)$ and respiratory resistance $(R$ rs $)$ measured by the forced oscillation technique in a sleep apnoea-hypopnoea syndrome patient at different levels of continuous positive airway pressure $\left(\mathrm{CPAP} ; \mathrm{CPAP}=4 \mathrm{cmH} \mathrm{H}_{2} \mathrm{O}(\mathrm{a}, \mathrm{d}, \mathrm{g})\right.$; $\mathrm{CPAP}=$ $8 \mathrm{cmH}_{2} \mathrm{O}(\mathrm{b}, \mathrm{e}, \mathrm{h}) ; \mathrm{CPAP}=12 \mathrm{cmH}_{2} \mathrm{O}$ (c, f, i). ins.: inspiration. Modified from [49] with permission.

whereas, in the case of airway closure, FOT measures the effective impedance of the airway segment from the mask to the collapse site. The technique allows a continuous, automatic and real-time monitoring of airway impedance $[48,49]$ without disturbing the patient's sleep [50].

Figure 9 is an example of the signals recorded when FOT was applied to assess airway obstruction in a patient with SAHS during CPAP. The $5-\mathrm{Hz}$ oscillation pressure can be observed in the pressure and flow signals. The resistance computed from the quotient between oscillatory pressure and oscillatory flow exhibits a low value during expiration (upper airway open) and high values during inspiration (flow limitation). Figure 10 illustrates how FOT can be used to determine the optimal CPAP in patients with SAHS. At low CPAP $\left(4 \mathrm{cmH}_{2} \mathrm{O}\right)$, the patient experienced an obstructive apnoeic event (no flow, high oesophageal pressure swings) characterised by high resistance. When a suboptimal CPAP $\left(8 \mathrm{cmH}_{2} \mathrm{O}\right)$ was applied, the patient experienced hypopnoeas. The resistance signal showed recurrent inspiratory increases because the upper airway was open during expirations and obstructed during inspirations. An optimal CPAP of $12 \mathrm{cmH}_{2} \mathrm{O}$ completely reversed airway obstructions; breathing flow, $P$ oes and resistance attained normal values.

As in any other measurement recording mask flow, FOT is sensitive to air leaks caused by insufficient sealing between the mask and the patient's skin. In the case of an air leak, FOT underestimates actual patient impedance. Potential artefacts can be discarded, since air leaks are easily detected and quantified from the relationship between the CPAP applied and the constant-flow component in the pneumotachograph signal. In addition to its use in research studies to better characterise the mechanics of the upper airway [51-55], the FOT has been incorporated into some automatic CPAP devices to modulate the nasal pressure, depending on the degree of airway obstruction.

\section{Conclusion}

In recent years, the work developed at the research level has provided the clinician with improved tools to noninvasively assess respiratory mechanics during sleep in the routine setting. As ease of application is essential, most of these techniques are simple. Consequently, they allow a semiquantitative assessment of the physiological variables. Given that these techniques are focused to monitor different aspects of the sleep-related breathing disturbances (airflow, effort or obstruction), and given that each technique is potentially affected by artefacts, the combination of more than one technique is recommended. This would provide redundancy and consistency in the detection of respiratory sleep events, both during hospital polysomnography and in the homemonitoring setting. Future technical developments and optimisations in the monitoring of respiratory mechanics during sleep would result in improved tools for the diagnosis and treatment of patients with sleep apnoea-hypopnoea syndrome.

\section{References}

1. Remmers JE, DeGroot WJ, Sauerland EK, Anch AM. Pathogenesis of upper airway occlusion during sleep. $J$ Appl Physiol 1978; 44: 931-938.

2. White PD. Pathophysiology of obstructive sleep apnoea. Thorax 1995; 50: 797-804.

3. Condos R, Norman RG, Krihnasamy I, Peduzzi N, Goldring RM, Rappoport DM. Flow limitation as a noninvasive assessment of residual upper airway resistance during continuous positive airway pressure therapy of obstructive sleep apnea. Am J Respir Crit Care Med 1994; 150: 475-480.

4. Clark S, Wilson CR, Satoh M, Pegelow D, Dempsey JA. 
Assessment of inspiratory flow limitation invasively and noninvasively during sleep. Am J Respir Crit Care Med 1998; 158: 713-722.

5. Farré R, Montserrat JM, Rotger M, Ballester E, Navajas D. Accuracy of thermistors and thermocouples as flow-measuring devices for detecting hypopnoeas. Eur Respir J 1998; 11 : 179-182.

6. Norman RG, Ahmed MM, Walsleben JA, Rapoport DM. Detection of respiratory events during NPSG: nasal cannula/pressure sensor versus thermistor. Sleep 1997; 20: $1175-1185$.

7. Montserrat JM, Farré R, Ballester E, Felez M, Pastó M, Navajas D. Evaluation of nasal prongs for estimating nasal flow. Am J Respir Crit Care Med 1997; 155: 211-215.

8. Farré R, Rigau J, Montserrat JM, Ballester E, Navajas D. Relevance of linearizing nasal prongs for assessing hypopneas and flow limitation during sleep. Am J Respir Crit Care Med 2001; 163: 494497.

9. Thurnheer R, Xie X, Bloch KE. Accuracy of nasal cannula pressure recordings for assessment of ventilation during sleep. Am J Respir Crit Care Med 2001; 164: 1914-1919.

10. Ballester E, Badia JR, Hernandez L, Farré R, Navajas D, Montserrat JM. Nasal prongs in the detection of sleep related disordered breathing on the sleep apnoea hypopnoea syndrome. Eur Respir J 1998; 11: 880-883.

11. Lorino AM, Lorino H, Dahan E, et al. Effect of nasal prongs on nasal airflow resistance. Chest 2000; 118: 366-371.

12. Hosselet JJ, Norman RG, Ayappa I, Rapoport DM. Detection of flow limitation with a nasal cannula/pressure transducer system. Am J Respir Crit Care Med 1998; 157: 1461-1467.

13. Sériès F, Marc I. Nasal pressure recording in the diagnosis of sleep apnoea hypopnoea syndrome. Thorax 1999; 54: 506510 .

14. Hernandez L, Ballester E, Farre R, et al. Performance on nasal prongs in sleep studies. Spectrum of flow related events. Chest 2001; 119: 442-450.

15. Cohn MA, Rao AS, Broudy $\mathrm{M}$, et al. The respiratory inductive plethysmograph: a new non-invasive monitor of respiration. Bull Eur Physiopathol Respir 1982; 18: 643-658.

16. Sackner MA, Watson H, Belsito AS, et al. Calibration of respiratory inductive plethysmograph during natural breathing. J Appl Physiol 1989; 66: 410-420.

17. Zimmerman PV, Connellan SJ, Middleton HC, Tabona MV, Goldman MD, Pride N. Postural changes in rib cage and abdominal volume-motion coefficients and their effect on the calibration of a respiratory inductance plethysmograph. Am Rev Respir Dis 1983; 127: 209-214.

18. Whyte KF, Gugger M, Gould GA, Molloy J, Wraith PK, Douglas NJ. Accuracy of respiratory inductive plethysmograph in measuring tidal volume during sleep. $J$ Appl Physiol 1991; 71: 1866-1871.

19. Adams JA, Zabaleta IA, Stroh D, Johnson P, Sackner MA. Tidal volume measurements in newborns using respiratory inductive plethysmography. Am Rev Respir Dis 1993; 148: 585-588.

20. Kaplan V, Zhang JN, Russi EW, Bloch KE. Detection of inspiratory flow limitation during sleep by computer assisted respiratory inductive plethysmography. Eur Respir $J$ 2000; 15: $570-578$.

21. Phillipson EA, Remmers JE. Indications and standards for cardiopulmonary sleep studies. Am Rev Respir Dis 1989; 139: $559-568$

22. Montserrat JM, Ballester E, Olivi H, et al. Time-course of stepwise CPAP titration. Behaviour of respiratory and neurological variables. Am J Respir Crit Care Med 1995; 152: 1854-1859.

23. Loiodice C, Selek M, Loire M, Levy P, Pepin JL. Measurement of respiratory effort (esophageal pressure) and estimation of resistance of the upper airway in polysomnography: indications, limitations and results. Neurophysiol Clin 1998; 28: 507-520.
24. Masa JF, Corral J, Martin MJ, et al. Assessment of thoracoabdominal bands to detect respiratory effort-related arousal. Eur Respir J 2003; 22: 661-667.

25. Morel DR, Forster A, Suter PM. Noninvasive ventilatory monitoring with bellows pneumographs in supine subjects. J Appl Physiol 1983; 55: 598-606.

26. Brouillette RT, Morrow AS, Weese-Mayer DE, Hunt CE. Comparison of respiratory inductive plethysmography and thoracic impedance for apnea monitoring. J Pediatr 1987; 111: 377-383.

27. Pennock BE. Rib cage and abdominal piezoelectric film belts to measure ventilatory airflow. J Clin Monit 1990; 6: 276283.

28. Sackner MA, Krieger BP. Non invasive monitoring. In: Scharf SM, Cassidy SS, eds. Heart-lung interactions in health and disease. New York, Marcel Dekker, 1989; pp. 663-805.

29. Drummond GB, Nimmo AF, Elton RA. Thoracic impedance used for measuring chest wall movement in postoperative patients. Br J Anaesth 1996; 77: 327-332.

30. Boudewyns A, Willemen M, Wagemans M, De Cock W, Van de Heyning P, De Backer W. Assessment of respiratory effort by means of strain gauges and esophageal pressure swings: a comparative study. Sleep 1997; 20: 168-170.

31. Chow $P$, Nagendra $G$, Abisheganaden J, Wang YT. Respiratory monitoring using an air-mattress system. Physiol Meas 2000; 21: 345-354.

32. Neuman MR, Watson H, Mendenhall RS, et al. Collaborative Home Infant Monitor Evaluation (CHIME) Study Group. Cardiopulmonary monitoring at home: the CHIME monitor. Physiol Meas 2001; 22: 267-286.

33. Sackner MA, Adams JA. Piezoelectric sensors versus respiratory inductive plethysmograph. J Appl Physiol 2001; 88: 403-404.

34. Pitson DJ, Stradling JR. Autonomic markers of arousal during sleep in patients undergoing investigation for obstructive sleep apnoea, their relationship to EEG arousals, respiratory events and subjective sleepiness. J Sleep Res 1998; 7: 53-59.

35. Pitson D, Chhina N, Knijn S, van Herwaaden M, Stradling J. Changes in pulse transit time and pulse rate as markers of arousal from sleep in normal subjects. Clin Sci (Lond) 1994; 87: $269-273$

36. Pitson DJ, Sandell A, van den Hout R, Stradling JR. Use of pulse transit time as a measure of inspiratory effort in patients with obstructive sleep apnoea. Eur Respir J 1995; 8: 1669-1674.

37. Pitson DJ, Stradling JR. Value of beat-to-beat blood pressure changes, detected by pulse transit time, in the management of the obstructive sleep apnoea/hypopnoea syndrome. Eur Respir J 1998; 12: 685-692.

38. Smith RP, Argod J, Pepin JL, Levy PA. Pulse transit time: an appraisal of potential clinical application. Thorax 1999; 54: $452-458$

39. Argod J, Pepin JL, Levy P. Differentiating obstructive and central sleep respiratory events through pulse transit time. Am J Respir Crit Care Med 1998; 158: 1778-1783.

40. Gold AR, Schwartz AR. The pharyngeal critical pressure. The whys and hows of using nasal continuous positive pressure diagnostically. Chest 1996; 110: 1077-1088.

41. Farré R, Peslin R, Rotger M, Navajas D. Inspiratory dynamic obstruction detected by forced oscillation during CPAP. A model study. Am J Respir Crit Care Med 1997; 155: 952-956.

42. Boudewyns A, Punjabi N, Van de Heyning PH, et al. Abbreviated method for assessing upper airway function in obstructive sleep apnoea. Chest 2000; 118: 1031-1041.

43. Farre R, Rigau J, Montserrat JM, Buscemi L, Ballester E, Navajas D. Static and dynamic upper airway obstruction in sleep apnoea: role of the breathing gas properties. $A m J$ Respir Crit Care Med 2003; 168: 659-663.

44. Schwartz AR, Gold AR, Schubert N, et al. Effect of weight 
loss on upper airway collapsibility in obstructive sleep apnea Am Rev Respir Dis 1991; 144: 494- 498.

45. Schwartz AR, Schubert N, Rothman W, et al. Effect of uvulopalatopharyngoplasty on upper airway collapsibility in obstructive sleep apnea. Am Rev Respir Dis 1992; 145: $527-532$

46. Litman RS, Jennifer DO, Hayes L, et al. Use of dynamic negative airway pressure (DNAP) to assess sedative-induced upper airway obstruction. Anesthesiology 2002; 96: 342-345.

47. Schneider H, Boudewyns A, Smith PL, et al. Modulation of upper airway collapsibility during sleep: influence of respiratory phase and flow regimen. J Appl Physiol 2002; 93: 1365-1376.

48. Farré R, Rotger M, Montserrat JM, Navajas D. Analog circuit for real time computation of respiratory mechanical impedance in sleep studies. IEEE Trans Biomed Eng 1997; 44: 1156-1159.

49. Farre R, Rigau J, Montserrat JM, Ballester E, Navajas D. Evaluation of a simplified oscillation technique for assessing aireway obstruction in sleep apnoea. Eur Respir $J$ 2001; 17 : 456-461.

50. Badia JR, Farre R, Rigau J, Uribe ME, Navajas D, Montserrat JM. Forced oscillation measurements do not affect upper airway muscle tone or sleep in clinical studies. Eur Respir J 2001; 18: 335-339.

51. Navajas D, Farré R, Rotger M, Badia R, Puig-de-Ventós M, Montserrat JM. Assessment of airflow obstruction during CPAP by means of forced oscillation in patients with sleep apnoea. Am J Respir Crit Care Med 1998; 157: 1526-1530.

52. Lorino AM, Lofaso F, Duizabo $\mathrm{D}$, et al. Respiratory resistive impedance as an index of airway obstruction during nasal continuous positive airway pressure titration. $\mathrm{Am}$ J Respir Crit Care Med 1998; 158: 1465-1470.

53. Badia JR, Farré R, Montserrat JM, et al. Forced oscillation technique for the evaluation of severe sleep apnoea/hypopnoea syndrome: a pilot study. Eur Respir J 1998; 11: 11281134.

54. Badia JR, Farre R, Kimoff RJ, et al. Clinical application of the forced oscillation technique for CPAP titration in the sleep apnoea/hypopnoea syndrome. Am J Respir Crit Care Med 1999; 160: 1550-1554.

55. Randerath WJ, Parys K, Feldmeyer F, Sanner B, Ruhle KH. Self-adjusting nasal continuous positive airway pressure therapy based on measurement of impedance: A comparison of two different maximum pressure levels. Chest 1999; 116: 991-999. 